\title{
A Preliminary Evaluation of Supersonic Transport Category Vehicle Operations in the National Airspace System
}

\author{
Matthew C. Underwood ${ }^{1}$, Michael D. Guminsky ${ }^{2}$ \\ NASA Langley Research Center, Hampton, VA, 23681
}

\begin{abstract}
Several public sector businesses and government agencies, including the National Aeronautics and Space Administration are currently working on solving key technological barriers that must be overcome in order to realize the vision of low-boom supersonic flights conducted over land. However, once these challenges are met, the manner in which this class of aircraft is integrated in the National Airspace System may become a potential constraint due to the significant environmental, efficiency, and economic repercussions that their integration may cause.

Background research was performed on historic supersonic operations in the National Airspace System, including both flight deck procedures and air traffic controller procedures. Using this information, an experiment was created to test some of these historic procedures in a current-day, emerging Next Generation Air Transportation System (NextGen) environment and observe the interactions between commercial supersonic transport aircraft and modernday air traffic. Data was gathered through batch simulations of supersonic commercial transport category aircraft operating in present-day traffic scenarios as a base-lining study to identify the magnitude of the integration problems and begin the exploration of new air traffic management technologies and architectures which will be needed to seamlessly integrate subsonic and supersonic transport aircraft operations.

The data gathered include information about encounters between subsonic and supersonic aircraft that may occur when supersonic commercial transport aircraft are integrated into the National Airspace System, as well as flight time data. This initial investigation is being used to inform the creation and refinement of a preliminary Concept of Operations and for the subsequent development of technologies that will enable overland supersonic flight.
\end{abstract}

\section{Nomenclature}

$\begin{array}{ll}\text { ATM } & =\text { Air Traffic Management } \\ \text { BADA } & =\text { Base of Aircraft Data } \\ \text { ConOps } & =\text { Concept of Operations } \\ C S T & =\text { Commercial Supersonic Transport } \\ F L & =\text { Flight Level } \\ I A D & =\text { Dulles International Airport } \\ J F K & =\text { John F. Kennedy International Airport } \\ \text { NAS } & =\text { National Airspace System } \\ \text { NASA } & =\text { National Aeronautics and Space Administration } \\ \text { NextGen } & =\text { Next Generation Air Transportation System } \\ \text { NLR } & =\text { Dutch Aerospace Center } \\ \text { NM } & =\text { Nautical Mile } \\ \text { SID } & =\text { Standard Instrument Departure } \\ \text { STAR } & =\text { Standard Terminal Arrival Route } \\ \text { STONE } & =\text { Supersonic Transport Operations in the NAS Experiment } \\ T M X & =\text { Traffic Manager eXecutable }\end{array}$

${ }^{1}$ Research Aerospace Engineer, Crew Systems and Aviation Operations Branch, NASA Langley Research Center, Mail Stop 152, Hampton, VA 23681-2199, AIAA Associate Member.

${ }^{2}$ Research Aerospace Engineer, Crew Systems and Aviation Operations Branch, NASA Langley Research Center, Mail Stop 152, Hampton, VA 23681-2199. 


\section{Introduction}

E ver since Charles "Chuck" Yeager broke the sound barrier in his Bell X-1 rocket-propelled aircraft, aircraft designers and airlines have sought to move scores of passengers to and from destinations around the world at speeds faster than the speed of sound.

In the late 1950s, the rapid pace of aeronautical progress - with new turbojet-powered airliners flying twice as fast and twice as high as the propeller-driven transports they were replacing-promised even higher speeds in coming years. Concurrently, the perceived challenge to America's technological superiority implied by the Soviet Union's early space triumphs inspired a willingness to pursue ambitious new aerospace ventures. One of these ventures was the Supersonic Commercial Air Transport. This program was further motivated by proposals being made in both the Soviet Union and in a joint effort between Britain and France to build a supersonic airliner, a type of airplane that was expected to dominate the future of mid- and long-range commercial aviation. ${ }^{1}$ The U.S. program was brought to a halt before an aircraft was even built, but the Soviet effort and the joint venture between Britain and France continued. These two efforts resulted in the only two commercial aircraft in the history of aviation that have ever realized the vision of a commercial supersonic aircraft. The two aircraft, the joint Anglo-French Concorde, and the Soviet Union's Tupolev Tu-144 aircraft, were both Mach 2.0 aircraft that could cruise at altitudes of up to 60,000 feet. Of those two aircraft, Concorde was the only commercial aircraft to operate regularly at sustained speeds greater than Mach $1 .^{2}$

The National Aeronautics and Space Administration (NASA) Advanced Air Vehicles Program, Commercial Supersonic Transport Project, is conducting research and development on key technical challenges to realize commercially viable supersonic flight, including lowering the sonic boom signature of future supersonic transport aircraft, meeting community noise requirements, and minimizing or eliminating the impact of high altitude engine emissions, all while improving the efficiency of the airframe and design process from previous project instantiations. ${ }^{3}$ The research is critical to the eventual development of commercial supersonic transport (CST) aircraft that are authorized to fly over land. However, once these challenges are met, the manner in which this class of aircraft is integrated in the National Airspace System will become a potential constraint, if not barriers, due to the significant environmental, efficiency, and economic repercussions that their integration may cause.

NASA Langley Research Center has started conducting air traffic management studies of CST aircraft operations in the National Airspace System (NAS). There has been no known research conducted to date with a specific focus on the air traffic management integration of significant numbers of CST aircraft flying over-land routes in the NAS.

\section{Background}

Flying faster than any commercial transport category aircraft in the history of powered flight, Concorde provided a luxurious and speedy means of travel in the skies above the Atlantic for 27 years. It was capable of speeds up to Mach 2.04, cruised at altitudes up to 60,000 feet, and could fly from London to New York and back in the same amount of time it took a conventional aircraft to fly the one-way trip. ${ }^{4}$ Concorde first entered service in 1976, and flew until 2003. Twenty aircraft were built; six airframes were prototype and developmental aircraft, and seven each were delivered to Air France and British Airways. ${ }^{2}$

Concorde, however, flew in an airspace environment that is fundamentally different than the envisioned airspace in which future CST aircraft will operate. Concorde only flew supersonic over water and over unpopulated areas due to the effects of the sonic boom that it produced. ${ }^{5}$ Cruise flight was conducted at altitudes significantly higher than commercial subsonic traffic and, because there was a minimal number of vehicles, special air traffic controller handling could be applied without significant interruption of subsonic operations.

This research, conversely, is investigating flights of significant numbers of CST aircraft over the continental United States with the underlying assumption that the aircraft will produce a quieter sonic boom. The cruise altitudes of these vehicles are not expected to be above Flight Level (FL) 500. Nonetheless, background research has been conducted on Concorde to create a better understanding of CST aircraft operations.

\section{A. Historic Supersonic Transport Operations in the NAS}

When Concorde was still flying, scheduled operations were only conducted at only two airports in the continental United States-Dulles International Airport (IAD) and New York's John F. Kennedy Airport (JFK). During takeoff from either of these airports, Concorde was required to utilize noise-abatement takeoff procedures due to community noise concerns. ${ }^{5}$ Concorde presented air traffic controllers with a challenge, because the take-off procedures sometimes forced an opposite direction takeoff that resulted in the loss of both arrival and departure slots in the regular traffic flow. ${ }^{6}$ Concorde remained subsonic throughout this procedure, and, after lift-off, it would follow air traffic control guidance and climb to a subsonic cruise altitude. ${ }^{7}$ When the aircraft reached this subsonic cruise altitude, the Concorde would level-off, hold the Mach number constant at 0.95, and head out towards the Atlantic Ocean. ${ }^{5}$ 
New York Center controllers vectored Concorde out over the ocean as quickly as possible to approximately FL300 before clearing the aircraft to climb and accelerate to its cruise altitude and Mach number. ${ }^{6}$ According to experienced Concorde pilots, the climb and acceleration to the supersonic cruise was the most crucial phase of flight. ${ }^{5}$ The flight crew and air traffic controllers had to understand that it was acceptable to incur the fuel burn and flight time penalties for staying subsonic rather than interrupt the climb and acceleration to supersonic cruise. Additionally, the air traffic controllers understood that Concorde needed a clear corridor to accelerate and climb between when the afterburners were turned on (beginning of climb) to when they were turned off, which occurred either at Mach 1.7 or 15 minutes after they were turned on, whichever came first. ${ }^{5,7}$

Out over the Atlantic Ocean during the cruise phase of flight, Concorde was essentially clear of other traffic. Concorde flew special oceanic routes, and was given a block of altitude at FL500+ in which a parabolic arc was flown during the cruise, rather than holding a constant, non-varying cruise altitude. ${ }^{5,7}$ This arc was flown due to the high temperatures caused by the friction created by the supersonic air acting on the skin of the aircraft. ${ }^{7}$

During a descent, Concorde crews had two procedures - a noise-limited procedure which took sonic boom effects into account, and a procedure that was strictly performance-based. The noise-limited procedure was required flying into IAD or JFK. This procedure required a calculation of the point where the aircraft had to be subsonic. The flight crew would then plan the descent accordingly. Similar to the climb and acceleration to the supersonic cruise, a corridor clear of traffic was required to perform an uninterrupted descent. Concorde could hold its altitude at FL400+, but had to remain supersonic to do so. This intermediate level-off would affect the point at which the Concorde would become subsonic, and would possibly cause a sonic boom to reach populated land. ${ }^{5}$

Typically during its descent, controllers gave Concorde the right of way, and cleared out subsonic traffic. New York Center controllers typically would descend and slow Concorde further out to sea in the summer months to prevent sonic boom from affecting Long Island. Controllers often inserted subsonic traffic into the arrival flow behind the Concorde due to its speed in descent. This eliminated the problem of the Concorde overrunning other traffic; however, this technique created inefficiencies for the subsonic transport aircraft and resulted in the loss of some arrival slots. ${ }^{6}$ Concorde could perform a hold, although holds that lasted longer than 10 minutes often required a diversion to an alternate field for fuel considerations. ${ }^{5}$ Due to these fuel considerations, controllers typically gave priority to the Concorde for landing ahead of other traffic. ${ }^{6}$

There were no unusual reported problems in controllers' handling during the approach and landing phases of flight although the Concorde final approach speed was, on average, 10 to 20 knots faster than most subsonic aircraft. ${ }^{6,8}$ The Concorde was classified as a heavy for wake vortex concerns, requiring more separation on approach. ${ }^{6}$

\section{Experiment Objective}

An experiment was conducted to provide an initial investigation evaluating the integration of commercial overland supersonic aircraft operations into the NAS. This study did not investigate any new flight deck or systematic concepts, but it investigated, at an air traffic management level rather than an aircraft-centric level, how a supersonic aircraft may interact with current subsonic NAS traffic. The resultant data will drive the subsequent development of tools and technologies that will eventually enable the safe, efficient, and seamless integration of CST aircraft into a Next Generation Air Transportation System (NextGen) NAS. Additionally, this data will inform a concept of operations that includes procedures for both air traffic controllers and flight crews enabling the seamless integration of CST aircraft without an objectionable increase to either flight crew or controller workload and without special handling procedures like those used for Concorde.

\section{B. Assumptions Made Regarding Future Supersonic Transport Operations in the NAS}

In this initial study, several operational assumptions have been made. These assumptions and others will be tested in subsequent tests to assess their possible influence in design and operational efficiencies.

The major assumption is that sonic boom issues have been resolved through the design and configuration of the aircraft and that the current FAA restriction on overland supersonic flight ${ }^{9}$ has been lifted. This will allow for overland flights between major continental United States airports. NASA research in progress is considering the effects of overpressure and focused boom effects on flight planning and operations.

Additionally, it is assumed that supersonic flights between cities that are geographically close to one another (e.g., Boston to New York City) were not economically feasible. This assumption is due to the assumed inefficiency of achieving supersonic cruise conditions compared to the small amount of time spent at supersonic cruise.

Finally, it is envisioned that future CST aircraft operations in the National Airspace System will likely occur in a NextGen environment. The NextGen environment will better allow for the integration of CST aircraft into the NAS, rather than operating them in a distinct, segregated airspace. ${ }^{10,11}$ Special handling, similar to how air traffic controllers 
interacted with Concorde, is not an acceptable economic or practical solution to realize widespread commercial supersonic flight. For the purpose of this study, no changes to IFR procedures or flight rules were proposed or modeled.

\section{Experiment Design}

This experiment-entitled Supersonic Transport Operations in the NAS Experiment (STONE) — was a full factorial batch simulation. Each of the scenarios was deterministic, meaning that only one replicate was required to obtain sufficient statistical power for the analysis. Additionally, all of the independent variables were discrete.

The study was formed to find solutions to three research questions:

1) What possible encounter characteristics (geometry, relative speed, and altitude) may be faced if CST aircraft flew with current-day levels of traffic?

2) What are the relative impacts of various assumed climb and descent profiles on flight time for a CST aircraft?

3) What is the approximate time savings for a supersonic transport aircraft compared to a modern-day subsonic transport aircraft flying the same route?

\section{A. Simulation Environment}

A joint NASA-NLR simulation tool called the Traffic Manager eXecutable (TMX) hosted in the NASA Langley Research Center Air Traffic Operations Laboratory served as the simulation platform for this study. TMX was chosen due to its ability to execute in a fast-time mode and its ability to simulate aircraft that are capable of supersonic speeds.

For this initial study, a generic fighter aircraft model capable of supersonic flight was used. This generic fighter aircraft model (BADA Model: FGTN) was used as a surrogate for the NASA N+2 supersonic vehicle. This model was used for convenience and is not representative a future CST aircraft. The impact of this assumption was not considered to be significant, but it will be tested in future experiments.

The TMX-inherent conflict detection algorithm was used to record encounters. This algorithm would record an encounter if a subsonic traffic aircraft encroached any space within a volume of 5 nautical miles (nm, radius) and height of \pm 1000 feet from the CST aircraft aircraft's current altitude. ${ }^{12}$

\section{B. Operational Assumptions}

Within this study, it is assumed that CST aircraft will maneuver similar to subsonic aircraft during the initial climb, arrival, and approach phases of flight, so those phases of flight will not be examined. The flight routes in this study began at the end of a Standard Instrument Departure (SID) of a major continental United States airport, flew direct routes, and ended at the transition to a Standard Terminal Arrival Route (STAR) of another major continental United States airport. These direct routes were created from great circle connections that began at the end of a SID and ended the transition to a STAR. These routes consisted of segments including the initial ascent from the end of the SID to an intermediate subsonic cruise altitude, the subsonic cruise phase, the supersonic acceleration and climb to supersonic cruise altitude phase, the supersonic cruise phase, and the supersonic deceleration and descent to the STAR, which are depicted in Figure 1. When the CST aircraft reaches the STAR, it is assumed that the aircraft will be at a comparable altitude (FL390 or less) and speed (Mach 0.84 or less) to modern subsonic traffic.

Following the Concorde operational concepts, this study also assumed that CST aircraft will require an uninterrupted supersonic acceleration and climb to cruise altitude (i.e., no intermediate level-off clearances during acceleration and climb to cruise altitude). As well, it is assumed that there be an uninterrupted supersonic deceleration and descent from cruise altitude to an intermediate altitude (i.e., no level-off clearances may be commanded until the CST aircraft slows to high-subsonic speeds which, for this study, was Mach 0.84).

\section{Scenario Description}

The CST aircraft was initialized at the end of a SID, flying at 250 knots indicated airspeed and at an altitude of FL180, in level flight. Soon thereafter, the CST accelerated toward Mach 0.84 and climbed (Figure 1, Phase 1).

The scenarios included a provision for an intermediate subsonic level-off altitude, representing the case where an air traffic controller might have to hold a CST aircraft at a lower altitude than its desired cruise altitude and at a subsonic speed. If an intermediate subsonic level-off was required (Figure 1, Phase 2), the aircraft accelerated to and then maintained Mach 0.84 and held the intermediate subsonic cruise altitude. The CST aircraft flew at that altitude for a predetermined segment length, after which it accelerated to its supersonic cruise Mach and climbed to its supersonic cruise altitude (Figure 1, Phase 3). 
If no level-off altitude was required, the CST aircraft climbed and accelerated unabated to its supersonic cruise altitude and supersonic cruise Mach number. In the schematic, the CST aircraft transitioned directly from Phase 1 to Phase 3.

The CST aircraft cruised at FL470 and Mach 1.6 (Figure 1, Phase 4). The CST aircraft maintained this cruise Mach and altitude to a calculated top-of-descent point.

After beginning its descent (Figure 1, Phase 5), the CST aircraft followed a flight profile that mirrored the ascent (i.e., the provision for an intermediate subsonic level altitude was added). If the intermediate subsonic level-off segment length is zero, the CST aircraft descends from the calculated top of descent point directly to the transition to the STAR. The CST aircraft reached the transition to the STAR at its subsonic level-off altitude (if no subsonic altitude level existed, the CST aircraft reached the transition to the STAR at FL395) and at a speed of Mach 0.84.

If required, the intermediate subsonic level-off altitude and segment length were the same in the descent as they were in the ascent, as shown in Figure 1, Phase 6.

The geographic coordinates for each waypoint in the trajectory were calculated to ensure that the flight profiles for the CST aircraft were symmetric. To achieve the speed and altitude requirements for the specific flight profile flown, speed and altitude constraints were commanded at each waypoint in the flight.

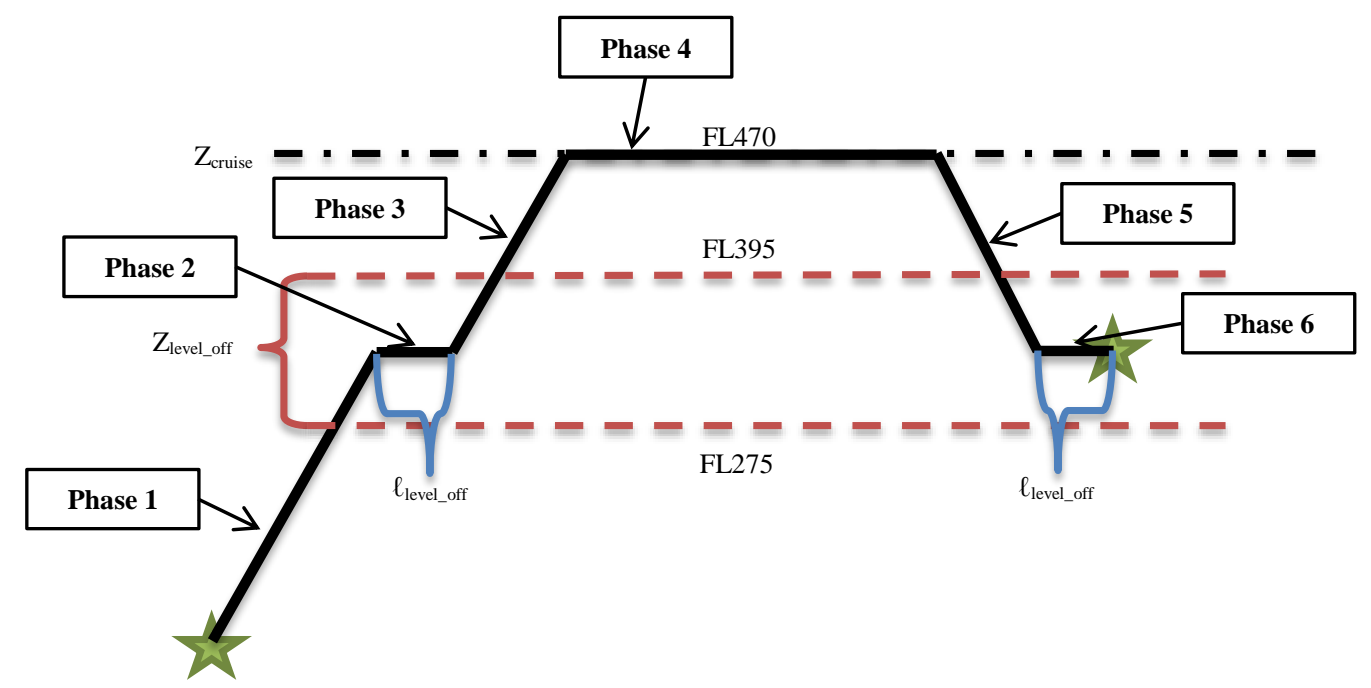

Figure 1: Schematic of Commercial Supersonic Aircraft Trajectory

\section{Independent Variables}

The independent variables in this study were: 1 ) the aircraft route; 2) the departure time; 3 ) the length of the intermediate subsonic level-off segment before the CST aircraft is cleared to climb to its cruise altitude and accelerate to its cruise Mach number; and, 4) the altitude at which that level off occurs.

\section{Aircraft route}

The batch experiment used existing subsonic NAS traffic with supersonic traffic operations added between selected US hub airports. Several candidate airports were chosen to create a representative sample between which routes were established. Table 1 displays the list of candidate airports (using airport identifiers).

Table 1: Candidate Airports for STONE

\begin{tabular}{|l|l|l|l|l|l|l|l|l|l|l|l|l|l|}
\hline \multicolumn{10}{|c|}{ Candidate Airports for STONE } \\
\hline KSEA & KSFO & KLAX & KLAS & KPHX & KDEN & KDFW & KIAH & KORD & KATL & KMIA & KIAD & KJFK & KBOS \\
\hline
\end{tabular}

An analysis was performed to choose city pairs from these candidate airports for which CST aircraft would be deemed practical. The feasibility of a flight route was determined by the time spent at a supersonic Mach number. Based upon the modeled aircraft flight characteristics, it was determined that a minimum practical distance between cities was $800 \mathrm{~nm}$. This assumption was because the simulated aircraft model could not reach the desired cruise Mach number of Mach 1.6 and the desired cruise altitude of FL470 before it had to begin its descent into the transition to 
the arrival with less than 800 nautical miles between city pairs, meaning that the effective time that a CST aircraft spent at its cruise Mach number and cruise altitude was 0 minutes. The modeled trajectory to determine the minimum feasible distance began at the end of a SID, included a 100 nautical mile level off for the CST aircraft at FL275 at both Phase 2 and Phase 6 of the trajectory illustrated in Figure 1, and ended at the transition to a STAR. This selection of city pairs and the assumption of a minimum distance between these pairs may neither be valid nor representative of an operational CST aircraft, but these assumptions are preliminary and arbitrary; they serve the purpose of ensuring an adequate length of supersonic flight segment.

The city pairs for this study are indicated by the plus sign in Table 2 .

Table 2: City Pairs used in STONE

\begin{tabular}{|c|c|c|c|c|c|c|c|c|c|c|c|c|c|c|c|}
\hline & \multicolumn{14}{|c|}{ Arrivals } \\
\hline & & KSEA & KSFO & KLAX & KLAS & KPHX & KDEN & KDFW & KIAH & KORD & KATL & KMIA & KIAD & KJFK & KBOS \\
\hline \multirow{14}{*}{ 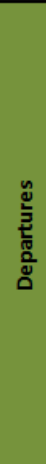 } & KSEA & & & & & + & + & + & + & + & + & + & + & + & + \\
\hline & KSFO & & & & & & + & + & + & + & + & + & + & + & + \\
\hline & KLAX & & & & & & + & + & + & + & + & + & + & + & + \\
\hline & KLAS & & & & & & & + & + & + & + & + & + & + & + \\
\hline & KPHX & & & & & & & + & + & + & + & + & + & + & + \\
\hline & KDEN & , & & & & & & & & + & + & + & + & + & + \\
\hline & KDFW & + & + & + & & & 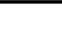 & & & & & + & + & + & + \\
\hline & KIAH & + & + & + & + & + & + & & & & & & + & + & + \\
\hline & KORD & + & + & + & + & + & & & & & & + & & & \\
\hline & KATL & + & + & + & + & + & + & & & & & & & & + \\
\hline & KMIA & + & + & + & + & + & + & & & + & & . & & + & + \\
\hline & KIAD & + & + & + & + & + & + & & + & & & & & & \\
\hline & KJFK & + & + & + & + & + & + & + & + & & & + & & & \\
\hline & KBOS & + & + & + & + & + & + & + & + & & & + & & & \\
\hline
\end{tabular}

The analysis showed that the results are not symmetric, meaning that for a route between departure airport "A" and arrival airport "B", a route may not exist departing from airport "B" and arriving at airport "A". This was due to the variance in the location of the end of the SID departing from a given airport and the transition point to a STAR to arrive at that same given airport.

\section{Departure times}

The second independent variable was the departure time of the CST aircraft. Each scenario consisted of four CST aircraft departing the same airport and flying the same direct route staggered by fifteen minutes each for each of the city pairs. The staggered departure times were chosen to directly address the first research question. The different departure times for each of the CST aircraft resulted in each aircraft experiencing a different traffic picture than the others. This was the most efficient way to expose the CST aircraft to a different traffic picture.

These four supersonic aircraft were added to a scenario where subsonic traffic flew along recorded flight plans on published airways from real-world air traffic data from April 1, 2013. Winds were not included in the simulation. The departure times are presented in Table 3.

\section{Table 3: Departure Times for CST Aircraft in STONE Scenarios}

\begin{tabular}{|c|c|c|c|}
\hline \multicolumn{4}{|c|}{ Time of Departure } \\
\hline $\mathrm{T}+0$ minutes & $\mathrm{T}+15$ minutes & $\mathrm{T}+30$ minutes & $\mathrm{T}+45$ minutes \\
\hline
\end{tabular}

\section{Length of Intermediate Level-off Segment}

The third independent variable was the length of the intermediate subsonic level-off segment that the CST aircraft flew prior to accelerating and climbing to its supersonic cruise Mach number and cruise altitude. The intermediate subsonic level-off lengths are presented in Table 4 and are depicted in Figure 1 as l level_off.

The intermediate subsonic level-off was scripted into the scenario since no human or simulated air traffic controller was used. The trajectories were symmetric, meaning that if the CST aircraft had an intermediate subsonic level-off segment with a length of $50 \mathrm{~nm}$ during its ascent, it also had an intermediate subsonic level off segment with a length of $50 \mathrm{~nm}$ after it descended from its cruise altitude. 
Table 4: Intermediate Subsonic Level-Off Lengths used in STONE

\begin{tabular}{|c|c|c|}
\hline \multicolumn{3}{|c|}{ Level-off Segment Length (NM) } \\
\hline $0 \mathrm{NM}$ & $50 \mathrm{NM}$ & $100 \mathrm{NM}$ \\
\hline
\end{tabular}

The different lengths for the intermediate subsonic level-off segment directly impacted each of the three research questions. These different lengths resulted in the CST aircraft encountering different subsonic traffic aircraft as well as affecting the duration of the flight.

\section{Altitude of Intermediate Level-off Segment}

The fourth and final independent variable was the altitude at which the intermediate subsonic level-off segment began. The values of the intermediate subsonic level-off altitudes were set at altitudes, shown in Table 5, which ended in $500 \mathrm{ft}$ (FL275, FL295, etc.). These non-IFR cruise altitudes were deliberately chosen in order to examine interactions with traffic in a large altitude block while minimizing the total number of scenarios. For example, instead of having two scenarios that had intermediate subsonic level-off segments at FL350 and FL360, one scenario was created with an intermediate subsonic level-off segment of FL355. The CD algorithm onboard a CST aircraft in the scenario with an intermediate subsonic level-off segment of FL355 would record intrusions at both FL350 and FL360. The results were then post-processed to ensure that conflicts that would not have happened due to procedural altitude separation were not counted in the data set.

The intermediate subsonic level-off altitudes are presented in Table 5 and displayed graphically in Figure 1 as $Z_{\text {level_off. }}$

Table 5: Intermediate Subsonic Level-Off Altitudes used in STONE

\begin{tabular}{|l|l|l|l|l|l|l|l|}
\hline \multicolumn{7}{|c|}{ Level-off Segment Altitude (FL) } \\
\hline None & FL275 & FL295 & FL315 & FL335 & FL355 & FL375 & FL395 \\
\hline
\end{tabular}

The different altitudes for the intermediate subsonic level-off segment directly impacted each of the three research questions. These different altitudes resulted in the CST aircraft encountering different subsonic traffic aircraft during the flight and it also affected the duration of the flight.

A special "best-case" scenario was examined for each city pair where the intermediate subsonic level-off segment length was zero and the altitude was "none". This implies that the CST aircraft was cleared to climb and accelerate from the end of the SID to its cruise altitude and cruise Mach number without the need to level-off. Additionally, since the trajectory of the CST aircraft was symmetric, the CST aircraft would descend and decelerate continuously from its calculated top-of-descent point to the transition to the STAR at the arrival airport.

\section{Results and Discussion}

Using 4 CST aircraft (one aircraft departing at each of the four departure times), with 113 city pairs, 2 intermediate altitude lengths and 7 intermediate subsonic cruise altitudes, as well as the special condition where there was no intermediate subsonic level-off, resulted in 1,695 scenarios and approximately 95 hours of TMX simulation time to compute the subsonic and supersonic traffic encounters, as well as to get flight times for the CST aircraft. These data were analyzed to address the three research questions.

\section{A. Dependent Measures}

This study used several dependent variables:

1) Planar encounter geometry of a detected conflict between the supersonic and subsonic traffic;

2) Number of detected conflicts/encounters;

3) Location along the trajectory of the encounters; and,

4) Three calculated flight times: a) the total flight time from the end of the SID to the transition to the STAR; b) the time spent by the CST aircraft at its cruise altitude; and, c) the time spent by the CST aircraft at its cruise Mach number.

Each of the three dependent variables maps directly to the three research questions.

\section{B. Encounter Results and Discussion}

The encounter geometry between CST aircraft and subsonic traffic is calculated using data output from a conflict detection algorithm running in the simulation environment. These data include information about the heading of each 
aircraft when the intrusion occurred, the closest distance between the two aircraft during the intrusion, the altitude of each aircraft when the intrusion occurred, and both the planar and vertical speed of each aircraft when the intrusion occurred. Using this data, the angle of the encounter relative to the SST aircraft can be calculated in both planar and spatial coordinates and the relative closure speeds of the encounter can be calculated. Additionally, the data include information about the point at which the encounter occurred along the SST trajectory. A total of 2,331 encounters were recorded, but this number is inflated for analysis purposes. The number is artificially high due to the four CST aircraft's different departure times on each flight route. The specific count data presented in this subsection (Figures 2, 3, 4, and 5) should not be viewed as absolute answers, but rather as a means to see the trends in the data. The discussion of the results in this subsection will be explained using the data trends rather than the absolute numbers.

\section{Data Cleansing}

Since the level-off altitudes for the simulated CST aircraft were deliberately chosen to be between the standard IFR flight levels, the conflict detection algorithm detected conflicts in both the flight level altitude above the CST vehicle and the flight level below. For flights going east to west, the FAA requires that the cruise altitude be an even flight level (FL280, FL300, FL320, etc.) and for flights going from west to east, the cruise altitude must be an odd flight level (FL290, FL310, FL330, etc.).

Before any analysis was performed, the data were scrubbed to ensure that any encounter that would not have occurred in real life due to the procedural altitude separation would not be counted. For example, consider a CST aircraft in one of the scenarios that flew from IAD to LAX and leveled off at a subsonic speed at FL355 prior to climbing and accelerating to its cruise altitude and Mach number. If an encounter was reported with a traffic aircraft that was flying straight and level at FL350, this encounter was discarded since the actual level-off altitude for the CST aircraft would be FL360, and the two aircraft would be procedurally separated by 1000 feet in a real-world operation. However, in the same scenario, if an encounter was reported with a traffic aircraft that was flying straight and level at FL360, this encounter was recorded since the CST aircraft and the traffic aircraft would be at the same altitude. This reduced the total number of intrusions; most notably, eliminated all head-on intrusions that occurred when the CST aircraft was in level

Percent of Each Type of Planar Encounter, $N=2331$

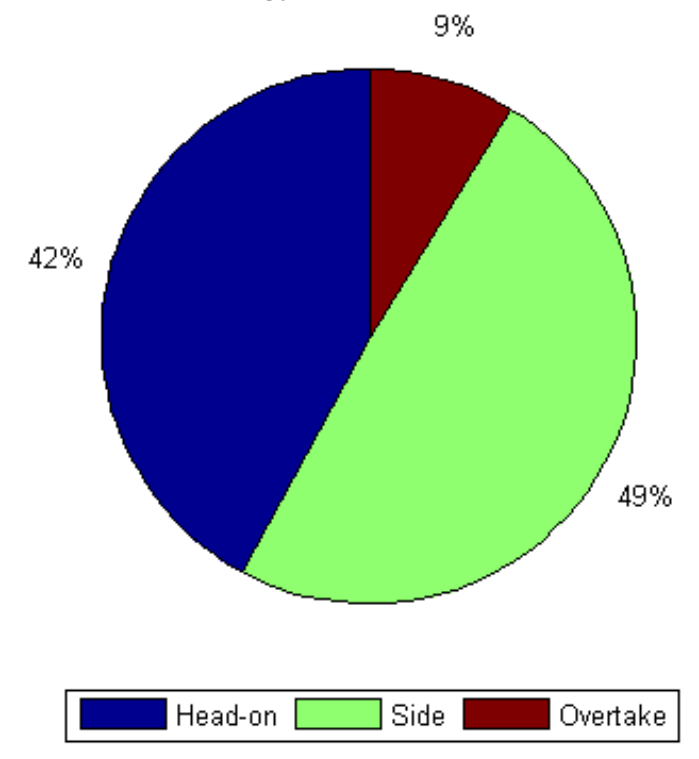

Figure 2: Percent of each type of encounter recorded in STONE

\section{Planar Encounter Results}

Using the angle of the encounter relative to the CST aircraft, the type of planar encounter was determined using four categories: head-on, side, and overtake. A head-on encounter occurred when the absolute value of the angle of the encounter relative to the CST aircraft was less than $45^{\circ}$. A side encounter occurred when the absolute value of the angle of encounter was between $45^{\circ}$ and $135^{\circ}$. Finally, an overtake encounter occurred when the absolute value of angle of the encounter was greater than $135^{\circ}$.

Figure 2 illustrates the percentage of each type of planar encounter. The data suggest that side and head-on encounters were the most prevalent.

All of the head-on encounters occurred during the climb and acceleration to cruise conditions and during the descent and deceleration to the transition of the STAR. No head-on encounters were recorded during the level-off segment or during the cruise phase of flight. 


\section{Encounters by Level-Off Segment Altitude and Length Results}

Of the four independent variables in this study, the altitude at which the intermediate subsonic level-off began and the length of the intermediate subsonic level-off were expected to have the largest effect on the number of intrusions. It was postulated that any intermediate subsonic level-off segments prior to the CST aircraft receiving a clearance from an air traffic controller to climb to its cruise altitude and accelerate to its cruise Mach number would negatively impact the number of intrusions experienced by that CST aircraft. Figure 3 illustrates the number of encounters versus both the altitude when the intermediate subsonic level-off segment is initialized and the length of the intermediate subsonic leveloff segment.

From the data in Figure 3, it was clear that CST aircraft flying the ideal trajectory-one that does not include an intermediate subsonic level-off segment-experienced fewer encounters than CST aircraft that were required to perform a level off prior to climbing and accelerating to its cruise altitude and Mach number. Additionally, most of the encounters experienced by a CST aircraft occurred when the altitude of the intermediate subsonic level-off segment was between FL270 and FL380.

Finally, it is evident that as the level-off length increases, the CST aircraft was prone to more encounters. This made sense because the aircraft is exposed for a longer duration to a dense traffic environment. Also, it should be noted that the relationship between encounters for a CST aircraft that is held for 50 nautical miles at an intermediate subsonic cruise altitude and one that is held for 100 nautical miles at the same intermediate subsonic cruise altitude was not linear. Future research may investigate this result, but since the commercial supersonic aircraft was subsonic at this point in the flight, coordinating and maintaining separation is not a problem that is unique to CST aircraft. The result may be a batch simulation peculiarityespecially since no human or simulated air traffic controllers were used in the study. This scenario is one that air traffic control should be able to handle.
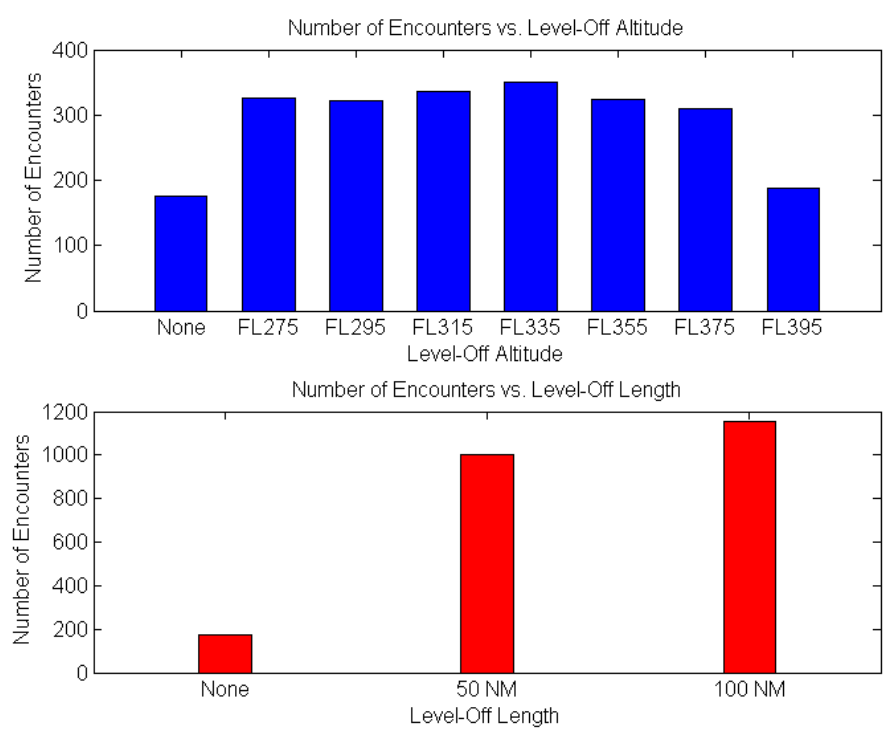

Figure 3: Number of Encounters by Level-Off Altitude and by Level-Off Length

Percent of Encounters at Each Location, $N=2331$

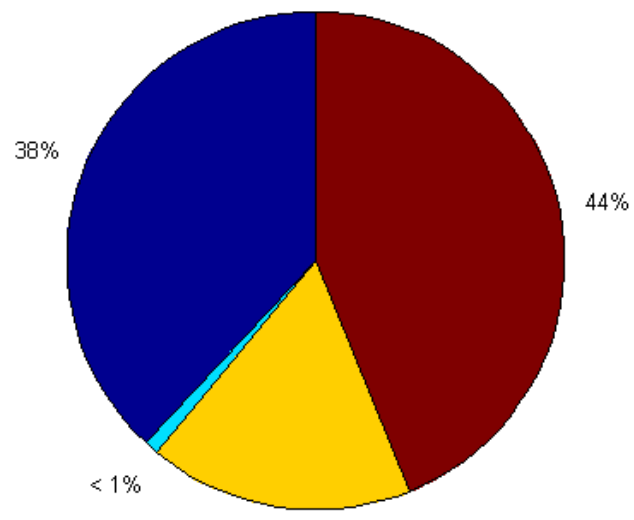

$17 \%$

Ascent to Cruise $\square$ Cruise $\square$ Descent from Cruise

During Level-off Segment

Figure 4: Percent of encounters at each location along the SST aircraft's trajectory

\section{Encounters by Flight Regime Results}

The phase of flight, or flight regime, where each encounter occurred was binned into four phases of the trajectory described in Figure 1-the intermediate subsonic level-off segment (Phase 2 and Phase 6), the ascent to the CST aircraft's cruise altitude from the intermediate subsonic level-off segment (Phase 3), the cruise altitude segment (Phase 4), and the descent from the CST aircraft's cruise altitude to the intermediate subsonic level-off segment, or to the 
transition of the STAR if no intermediate subsonic level-off segment exists (Phase 5). Figure 4 displays the percentage of encounters that occurred in each.

The data indicated that encounters were most likely to occur during the intermediate subsonic level-off segment. The next most likely flight phase was during the ascent from the intermediate subsonic level-off segment to the cruise altitude. Further analysis presented in Figure 5 showed that, for level-off altitudes greater that FL335, as the level-off altitude increases, the number of encounters experienced during the ascent to cruise altitude from the intermediate subsonic level-off segment phase of the CST aircraft's trajectory decreased. This result was expected, since the amount of congested airspace that the CST aircraft must climb through to reach its cruise altitude from the intermediate subsonic level-off segment is smaller.

Additionally, for level-off altitudes greater that FL335, as the level-off altitude increased, the number of encounters experienced during the descent from cruise altitude to the intermediate subsonic level-off segment phase of the CST aircraft's trajectory decreased. Again, this result was expected, since the amount of congested airspace that the CST aircraft must descend through to reach its intermediate subsonic level-off segment from its cruise altitude is, smaller.

Interestingly, there were encounters recorded when the CST aircraft was at cruise altitude. After examining the data, these encounters were caused by high-end business jets that were flying at FL470 on the recorded traffic day.

\section{Flight Time Results and Discussion}

Three flight times were calculated for the CST aircraft. The first flight time was the total flight time from the end of the SID to the transition to the STAR. The second and third flight times calculated were the time spent by the CST aircraft at its supersonic cruise altitude and its supersonic cruise Mach number, respectively.

\section{Total Flight Time Results and Discussion}

When analyzing the flights in aggregate, only four flights out of a total of 7796 $(0.05 \%)$ were shorter than one hour. Additionally, only 100 flights out of the total number of flights $(1.28 \%)$ were over 2.75 hours in length. Figure 6 displays a histogram of all of the flight times for all flights evaluated in STONE. The average flight time for all flights was approximately 1 hour and 52 minutes with a standard deviation of approximately 28 minutes. The median flight time was 1 hour and 50 minutes.

Further assessment of the data showed that as the altitude at which the intermediate subsonic level-off segment began increased, the flight time also increased up to an altitude of FL375. Evaluation of the CST aircraft's airspeeds confirmed these results.

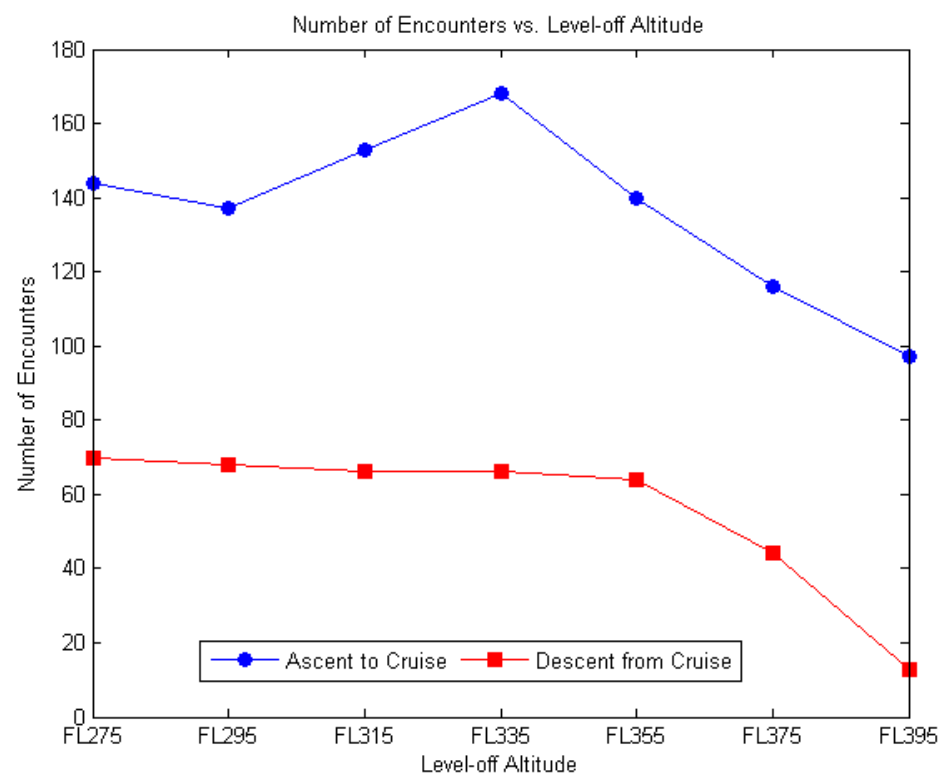

Figure 5: Number of encounters vs. level-off altitude for the ascent to cruise and descent from cruise phases of the SST aircraft trajectory

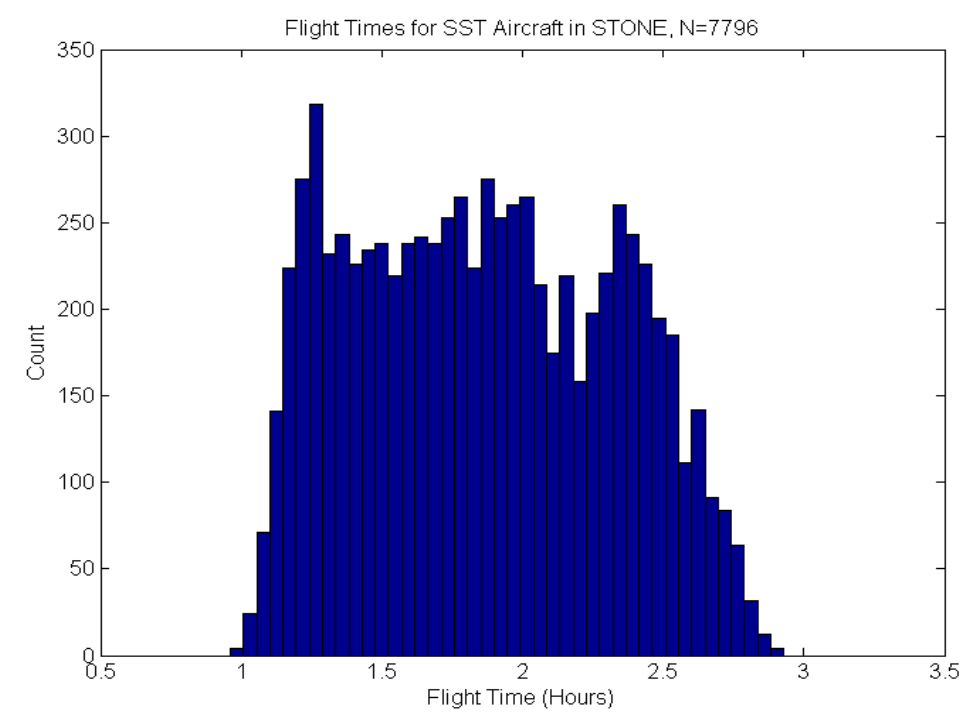

Figure 6: Flight Times for CST Aircraft in STONE 
In the scenarios, the CST aircraft was commanded to accelerate from 250 knots indicated airspeed (the speed the aircraft initialized at the end of the SID) to Mach 0.84. As the altitude of the intermediate level-off segment increased, the CST aircraft spent more time at Mach 0.84. Between FL375 and FL395, there was a very small decrease in flight time. It is hypothesized that this small decrease in flight time is due to the way that the trajectory was flown by the simulated aircraft. This result was seen across all flights in STONE. Further testing and analysis of the trajectory generator, the acceleration profile of the aircraft during a climb, and the flight guidance routines in TMX is required to confirm this hypothesis.

Additionally, as the length of the intermediate subsonic level-off segment increased, the flight time increased. This observation was intuitively easy to understand - as the length of the intermediate subsonic level-off segment increased, the percentage of the flight that the CST aircraft was held at a lower Mach number increased, thus causing a longer flight time.

\section{Time Spent by CST Aircraft at Cruise Altitude Results and Discussion}

The time spent by the CST aircraft at its cruise altitude was calculated using the aircraft's state information. The time the aircraft leveled-off at its cruise altitude was subtracted from the time that the aircraft reached its calculated top of descent point.

Figure 7 shows the times spent by all aircraft in STONE at the CST aircraft's cruise altitude. Analysis of this data showed that $36 \%$ of all flights spent less than one hour at the desired supersonic cruise altitude. The mean time spent at cruise altitude was approximately 1 hour and 13 minutes with a standard deviation of approximately 27 minutes. The median was approximately 1 hour and 12 minutes.

Across all flights and all trajectories, approximately $64 \%$ of the total flight time was spent at the CST aircraft's cruise altitude.

\section{Time Spent by CST Aircraft at Cruise Mach Number Results and Discussion}

The time spent by the CST aircraft at its cruise altitude was calculated using the aircraft's state information. The time the aircraft leveled-off at its cruise altitude was subtracted from the time that the aircraft reached its calculated top of descent point.

Figure 8 shows the times spent by all aircraft in STONE at the CST aircraft's cruise Mach number. Analysis of this data showed that $38 \%$ of all flights spent less than one hour at the desired supersonic cruise Mach number. The mean time spent at cruise Mach number was approximately 1 hour and 10 minutes with a standard deviation of approximately 27 minutes. The median was approximately 1 hour and 9 minutes.

Across all flights and all trajectories, $61 \%$ of the total flight time was spent at the supersonic commercial transport aircraft's cruise Mach number.

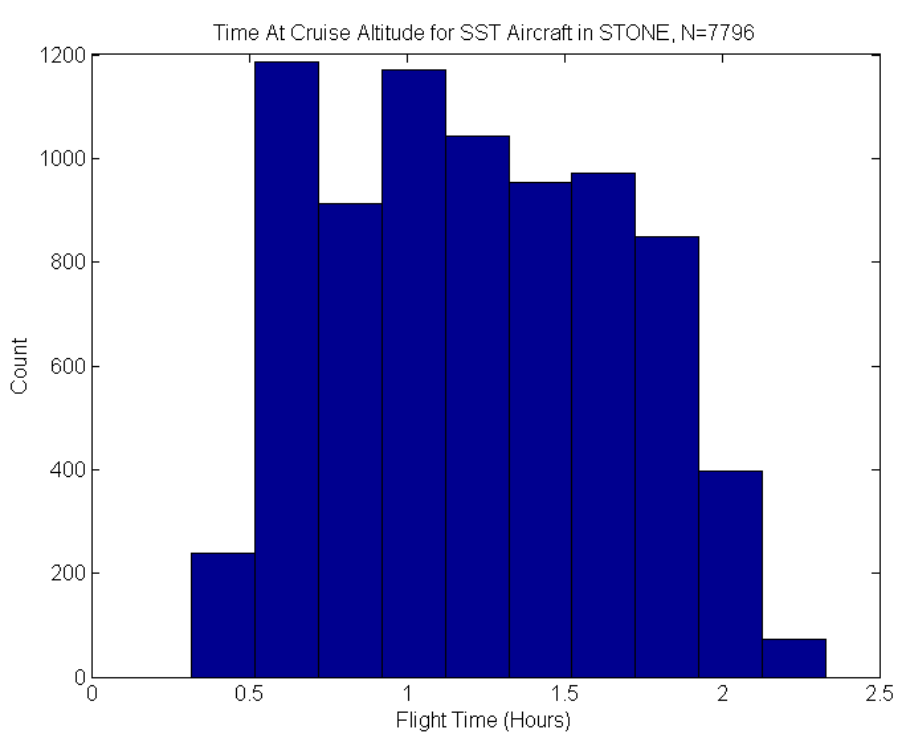

Figure 7: Time Spent by CST Aircraft at Cruise Altitude

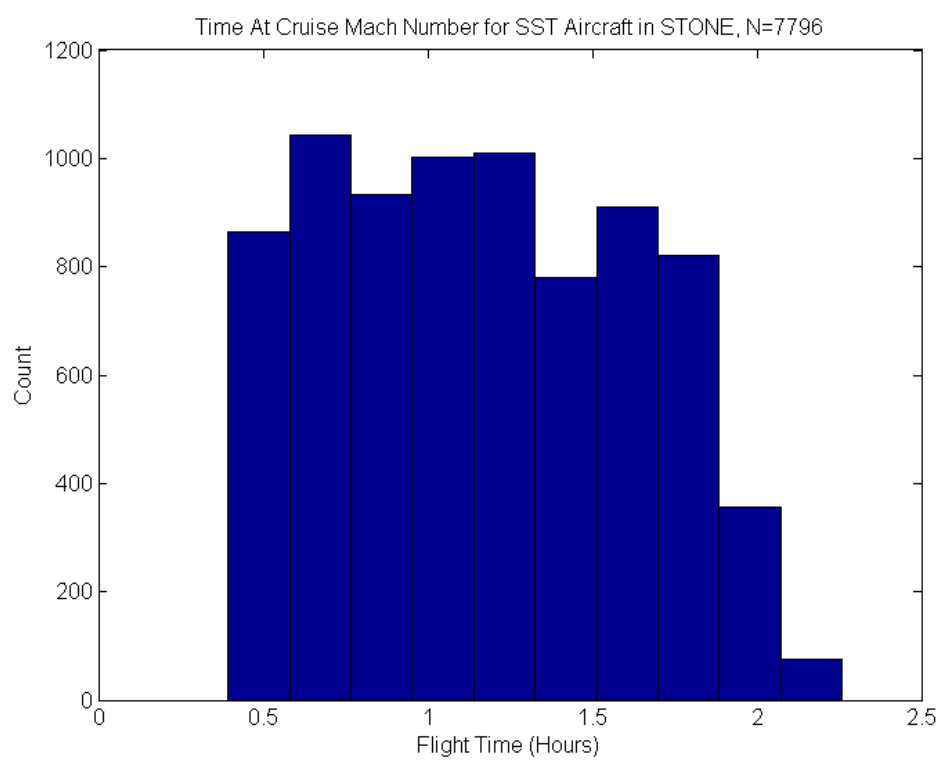

Figure 8: Time Spent by CST Aircraft at Cruise Mach Number 
These data suggested that the majority of the routes flown were economically feasible. If the time spent on a particular flight route at either the supersonic cruise altitude or the supersonic cruise Mach number was too short to make any impact on the total flight time, this route would not be considered economically feasible.

\section{Comparison between CST Aircraft and Subsonic Transport Aircraft}

In order to determine the time savings of a CST aircraft compared to a subsonic commercial transport aircraft flying the same route, scenarios were created in which a large subsonic commercial transport aircraft flew between the same cities that the CST aircraft flew. The subsonic commercial transport aircraft flew trajectories similar to the CST trajectories except the large category transport aircraft had a cruise altitude of FL420 and a cruise Mach number of 0.82 .

Using the total flight time data output by the subsonic scenarios, it was determined that CST aircraft flight times were, on average across all conditions, 53\% faster than the flight times flown by a subsonic aircraft flying the aforementioned comparable trajectories. Despite the incorporation of up to two $100 \mathrm{~nm}$ subsonic intermediate holds (one prior to the ascent and acceleration to cruise altitude and speed and one after the descent and deceleration from cruise altitude and speed), the flight time data shows that from SID to STAR, the CST cut the enroute flight times in half, on average. Thus, the flight time benefits of CST appear promising. Additional optimization may be offered if the subsonic SID and STAR constraints can be eliminated for supersonic aircraft and supersonic flight can be maintained for longer times, with shorter transitions from the origin and to the destination of each flight.

\section{Conclusion}

In conclusion, this study provides several key data that will relate to both the operations and procedures for operating a class of supersonic commercial transport vehicles in the National Airspace System as well as providing high-level justification for the economic benefits that operating these vehicles may bring.

The data suggest that there is a risk that an encounter may occur between subsonic commercial vehicles and CST vehicles if a controller keeps a supersonic vehicle at an altitude where there is a high density of subsonic traffic. This will create an economic cost for holding the supersonic aircraft and possibly increase the workload to air traffic controllers but it should be easily de-conflicted because all traffic are at subsonic speeds. Conversely, the data also shows significant potential encounters as the CST accelerates and climbs to or to a lesser extent, descends and decelerates from a supersonic cruise condition. This area represents the true challenge to airspace integration for CST aircraft. The present envisioned cruise altitude of FL470 is above most but not all commercial traffic, but the transition, as the history of Concorde illustrates, can be fuel-expensive and can interfere with subsonic traffic. This situation has the potential to add to a controller's workload, which should be avoided if possible. Additionally, there is a negative impact on the flight time if this situation arises, which in turn will reduce the economic benefit of operating these vehicles. Further reducing the benefit, if the CST aircraft is kept at a low altitude, the fuel penalty may be substantial. As typical, supersonic aircraft are optimized for supersonic flight; the Concorde could operate at subsonic cruise, albeit with sub-optimal efficiency, but more importantly, the transition to supersonic conditions and climbing design aspects of Concorde were severely limited and may limit the aircraft's range.

As such, a major limitation of this study was the use of an existing supersonic aircraft BADA model. The emerging $\mathrm{N}+2$ design data needs to be incorporated into this evaluation paradigm to more accurately explore the potential operational constraints that these unique vehicles might create in the NAS and explore architectures and technologies for Air Traffic Management to alleviate them. In addition, this work will develop new controller and flight deck tools to ensure smooth integration of CST aircraft into the NAS without workload burdens. Further, the effect of overpressure and focused boom must be part of the flight planning and integration solution.

\section{Acknowledgments}

The support of the Advanced Air Vehicles Program, and specifically, the Commercial Supersonic Transport Project manager, Mr. Peter Coen, is gratefully appreciated.

The author would also like to thank the members of the software development team and the Air Traffic Operations Laboratory operations staff who invested countless hours of hard work. This experiment and this paper would not be possible without their dedication.

\section{References}

${ }^{1}$ L. R. Benson, Quieting the Boom: The Shaped Sonic Boom Demonstrator and the Quest for Quiet Supersonic Flight, Washington, D.C.: National Aeronautics and Space Administration, 2013.

${ }^{2}$ British Airways, "Celebrating Concorde," 2014. [Online]. Available: http://www.britishairways.com/engb/information/about-ba/history-and-heritage/celebrating-concorde. [Accessed 20 May 2014]. 
${ }^{3}$ National Aeronautics and Space Administration, "The High Speed Project," 18 April 2013. [Online]. Available: http://www.aeronautics.nasa.gov/fap/high_speed.html. [Accessed 26 September 2014].

${ }^{4}$ The Museum of Flight, "Concorde," 2013. [Online]. Available: http://www.museumofflight.org/aircraft/concorde. [Accessed 20 May 2014].

${ }^{5}$ Concorde Operations, Debrief with Capt. John Hutchinson. [Film]. United States of America: National Aeronautics and Space Administration, 1995.

${ }^{6}$ P. Galligan, Interviewee, ATC Handling of Concorde at ZNY. [Interview]. 14 December 2012.

${ }^{7}$ British Airways, Concorde Flying Manual, Procedures and Techniques, Harmondsworth: British Airways, 1994.

${ }^{8}$ J. Keimig, Interviewee, ATC Handling of Concorde at ZDC. [Interview]. 12 December 2012.

${ }^{9}$ Federal Aviation Administration, "Civil Supersonic Airplane Noise Type Certification Standards and Operating," US Department of Transportation, Washington, D.C., 2008.

10"NASA and the Next Generation Air Transportation System (NextGen)," National Aeronautics and Space Administration, Washington, D.C., 2007.

${ }^{11}$ Federal Aviation Administration, "FAA's NextGen Implementation Plan," US Department of Transportation, Washington, D.C., 2014

${ }^{12}$ Federal Aviation Administration, "IFR Separation Standards," in Aeronautical Information Manual, Washington, 2014, Section 4-4-11. 